\title{
Histology and Histomorphometry of Kidney on Domestic Chicken (Gallus gallus domesticus) During Pre and Post Hatch
}

\author{
Deci Aryani ${ }^{1 *}$, Dian Masyitha ${ }^{2}$, Zainuddin $^{2}$, Muslim $\mathrm{Akmal}^{2}$, Teuku Zahrial \\ Helmi $^{3}$, Yudha Fahrimal ${ }^{4}$, Herrialfian Herrialfian ${ }^{3}$
}

\author{
${ }^{1}$ Study Program of Veterinary Education, Faculty of Veterinary Medicine, Universitas Syiah Kuala, Banda Aceh, \\ Indonesia \\ ${ }^{2}$ Laboratory of Histology, Faculty of Veterinary Medicine, Universitas Syiah Kuala, Banda Aceh, Indonesia \\ ${ }^{3}$ Laboratory of Biochemistry, Faculty of Veterinary Medicine, Universitas Syiah Kuala, Banda Aceh, Indonesia \\ ${ }^{4}$ Laboratory of Parasitology, Faculty of Veterinary Medicine, Universitas Syiah Kuala, Banda Aceh, Indonesia \\ *Corresponding author. E-mail: deciaryani47@gmail.com
}

\begin{abstract}
The purpose of this study was to determine the renal histology and histomorphometry of domestic chickens (Gallus galus domesticus) before and after hatching. The study involved in four treatment groups namely incubation period of 7 days (K1), 14 days (K2), and 20 days (K3), 7 days after hatching (K4) with six replications each. The results showed that the histological structure of kidney of domestic chicken in the incubation period of 7, 14, and 20 days and 7 days after hatching had a nephron consisted of glomerulus, Bowman's capsule, proximal convoluted tubule, and distal convoluted tubule. During the $7^{\text {th }}$ day incubation, the kidney of the chicken embryo was in the mesonephros phase. At the age of 14 and 20 days of the incubation the kidney of chicken embryo was in the metanephros phase. Post hatch on the $7^{\text {th }}$ day, cells that function as macrophages (namely mesangial cell) were found in endothelial cells and basal lamina of glomerular capillaries. Histomorphometry of glomerulus, Bowman's capsule, proximal convoluted tubule and distal convoluted tubule during the $14^{\text {th }}$ and $20^{\text {th }}$ days of incubation and on the $7^{\text {th }}$ day after hatches did not show any significant difference $(p<0.05)$. It can be concluded that the incubation period affects the histological structure of the renal cortex of domestic chicken embryos.
\end{abstract}

Keywords: Domestic chicken, histomorphometry, histology, renal cortex

\section{INTRODUCTION}

The kidneys are the main excretory organs that play an important role in the process of removing metabolic wastes [1]. The metabolic process produces waste products, which that if is not excreted, can harm the body [2]. According to Isnaeni [3], animals must have organs that function as means of excretion to dispose of these metabolic waste substances.

The structure of the kidney consists of the cortex and medulla. Microscopically, they contain three elements namely glomerulus which functions as a place for filtration, the proximal convoluted tubule as the reabsorption site, and the distal convoluted tubule as the augmentation site. These three elements function in the excretion process [4].
According to Tanuwidjaya [5], animal growth and development are divided into two stages, namely the prenatal and postnatal periods. In poultry flocks, during the prenatal stage the formation of the excretory device comes from the mesoderm seed layer which is the candidate for organogenesis [6]. There are three stages in the development of poultry kidneys, namely pronephros, mesonephros, and metanephros. Metanephros is the final stage of poultry kidney development and fully functional on the 15th day of the incubation period [7].

The development of the kidneys is very important in the excretion process. The excretion process occurs in the embryonic period and after hatching. Kurnia and Nuriliani [8] state that there are differences in histological and histomorphometric structures of kidneys of preadult and adult wader stingrays. However, studies on histological and histomorphometric features of the 
kidneys, especially native chicken embryos, have not been reported. Based on the above background, it is necessary to conduct a study to determine the histological and histomorphometric images of native chicken kidneys (Gallus gallus domesticus) before and after hatching.

This study aims to determine the histological and histomorphometric features of native chicken kidneys (Gallus galus domesticus) on the $7^{\text {th }}, 14^{\text {th }}, 20^{\text {th }}$ day of incubation, and $7^{\text {th }}$ day after hatching.

\section{MATERIALS AND METHODS}

\subsection{Research Design}

This laboratoric study used a completely randomized design (CRD). The research sample was obtained from the community farms of Limpok village, Aceh Besar. The samples were embryonic eggs. The samples were divided into four groups and each group consisted of six local chicken kidneys. This calculation was obtained using Federer's formula. Group I, II, and III were native chickens embryonic kidneys aged 7, 14 and 10 days whereas group IV was native chicken kidney 7 days after hatching. The kidney samples were subjected to histological preparations using Haematoxylin-Eosin (HE) staining.

\subsection{Kidney Sampling}

Free-range eembryonic chicken eggs were purchased from the farm of Limpok village residents, Aceh Besar. The eggs were incubated at $37-38{ }^{\circ} \mathrm{C}$ and a humidity of $60-70 \%$ in the Laboratory of Histology, Faculty of Veterinary Medicine, Universitas Syiah Kuala. For group I-III, the embryos were sacrified by cutting the placental blood vessels [9] and subjected to a laparotomy for kidneys collection. For group IV, chickens were sacrified slaughtering and subjected to a laparotomy for kidneys collection.

All kidney samples were cleaned with $0.9 \% \mathrm{NaCl}$ solution. One kidney sample from each embryo or chicken (left or right) was fixed in NBF solution and transferred to $70 \%$ ethanol solution as a stopping point until the dehydration process was carried out.

\subsection{Histological Preparation}

The histological preparation of kidney samples referred to the method of Kiernan [10]. This process started from tissue dehydration with a gradient concentration of ethanol solution $(80 \%, 90 \%$, 95\%, absolute I and absolute II), clearing in xylol solution three times, tissue infiltration in paraffin three times, embedding with liquid paraffin and and blocking solid paraffin. The kidney block was then cut using a microtome with a thickness of $3 \mu \mathrm{m}$. The incision was placed on a waterbath, mounted to an object glass and incubated on a slide warmer. The preparate was stained using Haematoxyllin-Eosin (HE) solution, mounted with Entellan ${ }^{\circledR}$ and closed with a cover glass.

\subsection{Microscopic Observation}

The preparate was observed using a light microscope (Olympus CX31) with a magnification of 400 times, and photographed using Toupview software.

\subsection{Histomorphometric Measurement}

Histomorphometric measurements of kidneys were focused on glomerulus, Bowman's capsule, proximal convoluted tubule, and distal convoluted tubule. The measurement was performed in duplicate.

\subsection{Data Analysis}

Histological data were analyzed descriptively whereas histomorphometric data were statistically analyzed using the analysis of variance (ANOVA), followed by the Duncan test with a level of significance of 0.05. The analysis was carried out using SPPS 24 program for Windows (IBM, USA).

\section{RESULTS AND DISCUSSION}

\subsection{Histological Structure of Kidney of Domestic Chicken}

\subsubsection{The Incubation Period of 7 Days}

The kidney of chicken embryo after 7 days of incubation showed nephrons consisting of glomerulus, Bowman capsule, proximal convoluted tubule, and distal convoluted tubule. The findings were in accordance with those stated by Purnomo [11]. Each kidney has a nephron, the smallest functional unit of kidney consisting of the proximal convoluted tubule, distal convoluted tubule, glomerulus, and Bowman's capsule.

On the $7^{\text {th }}$ day of incubation period, the embryonic kidneys of native chickens are in the mesonephros phase. This phase is characterized by the development of the kidneys that are not fully developed. The glomerulus still has many empty spaces due to glomerular capillaries have not formed dense webbing, yet. Podocyte cells have not shown clear boundaries with capillary glomeruli. The flattened epithelial cells of the Bowman's capsule are not clearly visible, but the capsular space (Spatium capsule) is clearly visible. The results of this study are in accordance with those previoulsy reported by other researchers $[7,12]$.

The proximal tubule have no brush border so that its lumen is still wide, as reported by Nutriana and Jatman [13]. The histological structure of the renal cortex of native chicken embryos aged 7 days of incubation can be seen in Figure 1. 


\subsubsection{The Incubation Period of 14 Days}

On the $14^{\text {th }}$ day of incubation period, the kidney of native chicken embryos had already developed compared to those on the $7^{\text {th }}$ day of incubation period. The lobes of the kidney were clearly demarcated and covered by a loose connective tissue called the renal capsule. The glomerular capillaries form a dense webbing so that they almost fill in the capsule space. Bowman's capsule is composed of a layer of flat epithelium but has no clear boundaries between the epithelium. Podocyte cells that help in the filtration process already started to have clear boundaries with the glomerular capillary matting. The proximal convoluted tubule has formed a brush border that looks like fine hairs and the lumen becomes narrow. In the distal convoluted tubule, the nucleus is more numerous. These findings were in accordance with that reported by Junqeira and Carnairo [14]. Furthermore, Bellairs and Osmond [7] reported that at the $14^{\text {th }}$ day of incubation, the kidneys of poultry embryo enter the metanephros phase, the final stage of the kidney formation process. According to Surjono [15], although the kidneys have been formed, they have not yet fully functioned because the excretory function during the embryonic period is still carried out by the placenta.

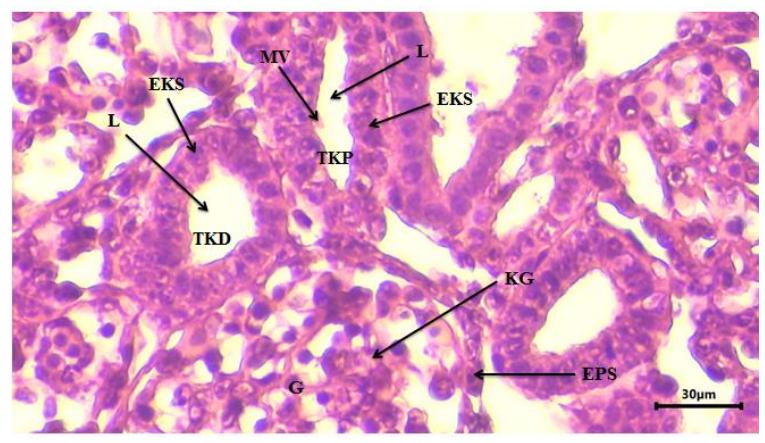

Figure 1 Histology of the renal cortex of native chicken embryos in the $7^{\text {th }}$ day of incubation. Glomerulus $(G)$, capillary glomeruli $(\mathrm{KG})$, flat epithelium layer (EPS), proximal convoluted tubule (TKP), layer cuboid epithelium (EKS), lumen (L), microvilli (MV), distal convoluted tubule (TKD). HE staining. Magnification 400x and Scale bar $30 \mu \mathrm{m}$.

The development of kidneys occurs in three stages namely pronephros, mesonephros, and metanephros. Pronephros differentiates at 36 hours of incubation and degenerates at 40-45 hours of incubation. Mesonephros began to differentiate at 40-45 hours of incubation and began functioning on day 5 of the incubation period. Metanephros differentiates at 4-5 days of incubation and begins to function at 11 days of incubation and only fully functionig on day 15 of the incubation period [7]. The histological structure of the renal cortex of native chicken embryos, the $14^{\text {th }}$ day of incubation can be seen in Figure 2 .

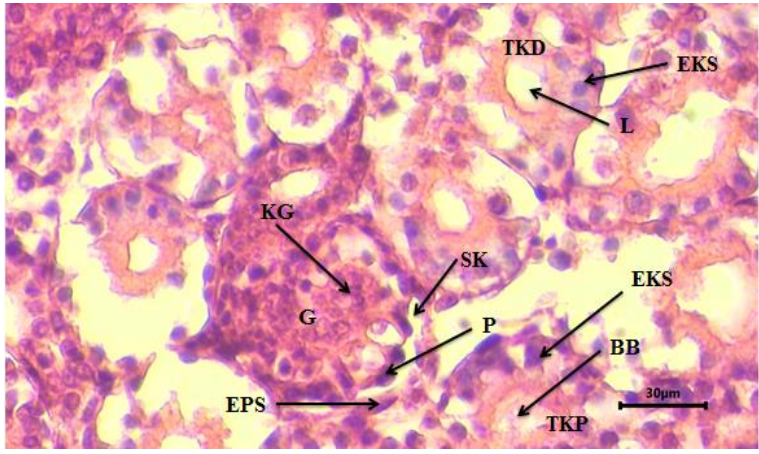

Figure 2 Histology of the renal cortex of native chicken embryos on the $14^{\text {th }}$ day of incubation. Glomerulus $(G)$, capillary glomeruli $(\mathrm{KG})$, flat epithelium layer (EPS), podocyte $(\mathrm{P})$, capsular spatium $(\mathrm{SK})$, proximal convoluted tubule (TKP), layer cuboid epithelium (EKS), brush border (BB), tubule distal contortion (TKD), lumen (L). HE staining. Magnification 400x and Scale bar $30 \mu \mathrm{m}$.

\subsubsection{The Incubation Period of 20 Days}

The histological structure of the renal cortex of native chicken embryos on the $20^{\text {th }}$ day of incubation was perfect compared to those on the $7^{\text {th }}$ and $14^{\text {th }}$ day of incubation. The glomerulus, Bowman's capsule, proximal and distal convoluted tubules have a distinct shape. The podocyte cells in the glomerulus appear to surround the capillaries of the glomeruli. The epithelium of the Bowman's capsule is clearly visible. In the proximal tubule, the brush border is thicker and denser. The nucleus of the distal convoluted tubule is more numerous and round in shape.

On the $20^{\text {th }}$ day of the incubation period, the kidney embryo of native chickens is definitive and functioning normally (metanephros). The excretion system of chicken embryos is no longer supported by the placenta because the egg yolk has been absorbed into the embryo's abdomen and it is in the hatching period. As reported by Kusumawati et al. [9] in their research on embryo development and sex determination of DOC of super Javanese chickens, chicken eggs hatch on the $20^{\text {th }}$ or $21^{\text {st }}$ day of the incubation period. The histological structure of the renal cortex of native chicken embryos, the incubation period of the $20^{\text {th }}$ day can be seen in Figure 3 .

\subsubsection{On the $7^{\text {th }}$ Day After Hatching}

On the $7^{\text {th }}$ day after hatching, the histological structure of native chicken kidneys was definitive and functioning normally (metanephros). The cortex and and medulla consisted of the glomerulus, proximal convoluted tubule, and distal convoluted tubule can be clearly distinguished. In the glomerulus, there are already cells that function as macrophages, namely mesangial cells located on endothelial cells and the basal lamina of the glomerular capillaries. In the embryonic period the 
body's defense system is run by the yolk. Mesangial cells were found, presumably because the yolk has ended the body's defense system. As reported by Nguyen et al. (2010), that chickens produce a unique immunoglobulin molecule called $\operatorname{IgY}$ which is functionally equivalent to mammalian IgG.

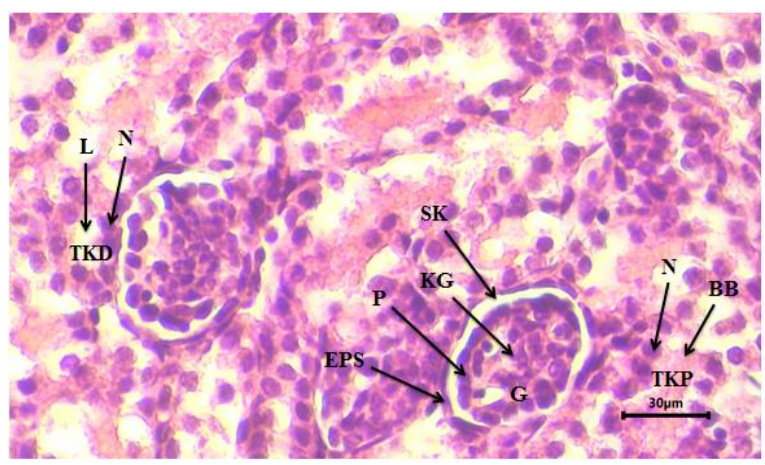

Figure 3 Histology of the renal cortex of native chicken embryos in the $20^{\text {th }}$ day incubation period. Glomerulus $(\mathrm{G})$, capillary glomeruli (KG), capsular spatium (SK), flat epithelium layer (EPS), podocyte (P), proximal convoluted tubule (TKP), nucleus $(\mathrm{N})$, brush border (BB), distal convoluted tubule (TKD), lumen (L). HE staining. Magnification 400x and Scale bar $30 \mu \mathrm{m}$.

After the $7^{\text {th }}$ day of hatching, the brush border on the proximal tubule looks denser and thicker. This is thought to be because the excretion process has been carried out by the kidneys so that the brush border has worked according to its role, namely helping in the reabsorption process [14]. The distal convoluted tubule had the numerous and round nuclei as well as faded cytoplasm after HE estaining. These are in accordance with the statement of Takashima and Hibiya [17], that the cytoplasmic color of the distal convoluted tubule is faded because there are fewer granules in the cytoplasm than in the proximal convoluted tubule. The histological structure of the local chicken renal cortex after the $7^{\text {th }}$ day of hatching can be seen in Figure 4.

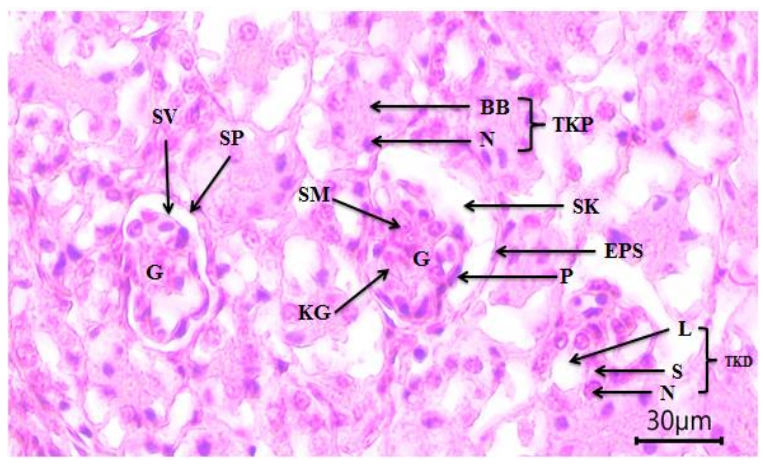

Figure 4 Histology of local chicken renal cortex after $7^{\text {th }}$ day of hatching. Glomerulus (G), capillary glomeruli (KG), flat epithelium layer (EPS), capsular spatium (SK), podocytes $(\mathrm{P})$, mesangial cells $(\mathrm{SM})$, parietal stratum (SP), visceral stratum (SV), proximal convoluted tubules (TKP), nucleus (N), brush border (BB), distal convoluted tubule (TKD), cytoplasm (S), lumen (L). HE staining. Magnification 400x and Scale bar $30 \mu \mathrm{m}$.

\subsection{Renal Histomorphometry of Domestic Chicken}

Histomorphometric measurement was only carried out on chicken embryos at the age of 14 and 20 days of incubation and on chicks at the age of 7 days post hatching. The histomorphometry of embryonic kidneys aged seven days of the incubation period could not be determined because the glomeruli and renal tubules were not clearly visible. Renal histomorphometry of domestic chicken embryo aged 14 and 20 days of incubation and aged seven days after hatching are presntred in Table 1.

Table 1. The histomorphometry of renal cortex of domestc chickens

\begin{tabular}{|l|l|l|l|}
\hline \multirow{2}{*}{} & \multicolumn{2}{c|}{ Age group } \\
\cline { 2 - 4 } \multicolumn{1}{c|}{ K1 } & \multicolumn{1}{c|}{ K2 } & \multicolumn{1}{c|}{ K3 } \\
\hline Glomerulus & $42.50 \pm 15.32$ & $42.86 \pm 2.54$ & $40.18 \pm 6.18$ \\
\hline Bowman's capsule & $7.21 \pm 4.72$ & $3.25 \pm 2.42$ & $5.94 \pm 4.55$ \\
\hline Proximal convoluted tubule & $46.53 \pm 25.41$ & $41.20 \pm 4.32$ & $40.01 \pm 6.99$ \\
\hline Distal convoluted tubule & $32.50 \pm 20.25$ & $41.62 \pm 5.09$ & $36.53 \pm 12.87$ \\
\hline
\end{tabular}

K1: The incubation period of the 14th day

K2: Incubation period of the 20th day

K3: After hatching the 7th day

Data in Table 1 shows the increased size of glomerulus from the incubation period of 14 and 20 days and on the $7^{\text {th }}$ day after hatching. The size of Bowman's capsule reduced from $7.21 \pm 4.72 \mu \mathrm{m}$ at day 14 of incubation period to $3.25 \pm 2.42 \mu \mathrm{m}$ at day 14 of incubation period, and increase again to $5.94 \pm$ $4.55 \mu \mathrm{m}$ at day 7 after hatching. The size of the proximal convoluted tubule decreased from $46.53 \pm$ $25.41 \mu \mathrm{m}$ at day 14 of incubation period to $40.01 \pm$ $6.99 \mu \mathrm{m}$ at at day 7 after hatching. The size of the distal convoluted tubule showed a similar pattern of change to the sze of Bowman's capsule.

The size of the glomerulus, Bowman's capsule, and proximal and distal convoluted tubules of native 
chicken kidneys were not significantly different between the ages of 14 and 20 days of incubation and age seven days after hatching. This is presumably because at the age of 14 and 20 days of incubation period and at the day seven after hatching poultry kidneys undergoe the same final developmental phase, namely metanephros [7].

The size of the glomerulus at the incubation period on $14^{\text {th }}$ and $20^{\text {th }}$ days increased, but decreased on the $7^{\text {th }}$ day after hatching. This presumably occurred due to increased workload in the glomerulus. In contrast to the Bowman capsule that had decreased size during the incubation period of $14^{\text {th }}$ and $20^{\text {th }}$ days, and increase on the $7^{\text {th }}$ day after hatching. These changes are thought to be due to an increase in the size of the glomerulus.

According to Wardani [18], the narrowing of the distance between the Bowman's capsule and the glomerulus can be caused by three factors, namely the enlargement of the glomerulus, the narrowing of the Bowman's capsule and their combination. The narrower distance between the Bowman's capsule and the glomerulus can lead to decreased filtration ability because the filtered blood cannot exit to the proximal convoluted tubule via the Bowman space. The widening of the Bowman space indicates that more and more filtrate enters the proximal tubule which can indicate glomerular atrophy. In the distal convoluted tubule there was an increase in size on the $14^{\text {th }}$ and $20^{\text {th }}$ days of incubation period and there was a decrease on the $7^{\text {th }}$ day after hatching. This is thought to be because the function of the distal convoluted tubule as a site of augmentation affects the change of cell size. Enlargement of cell size in organs is a response that occurs when there is an increase in the workload of a cell. The results of this study are in accordance with those presented by and Wardani [18] and Mayori et al. [19].

\section{CONCLUSION}

The incubation period affects the histological structure of the renal cortex of native chicken embryos. On the $7^{\text {th }}$ day of the incubation period, the kidneys of native chicken embryos are in the mesonephros phase and on the 14th and 20th days of the incubation period, the kidney embryos of native chickens have entered the metanephros phase. Histomorphometry of the renal cortex of native chickens at the incubation period of 14 and 20 days and 7 days after hatching did not show any significant differences.

\section{AUTHORS' CONTRIBUTION}

All authors equally contributed to the manuscript preparation and editing.

\section{ACKNOWLEDGMENTS}

The authors gratefully acknowledge the Faculty of Veterinary Medicine, Universitas Syiah Kuala, for the facility provided.

\section{REFERENCES}

[1] C. Abolnik, A current review of avian influenza in pigeons and doves (Columbidae).Vet. Microbiol. 170 (2014) p. 181-96.

[2] A. Candra, H.F. Trianto, M.I. Ilmiawan, Histological features of the cortex rat kidney (Rattus norvegicus) after discontinuation of monosodium glutamate exposure by mouth. Cerebellum J. 1(3) (2015) 202-220.

[3] M.C. Hasani, Ammonia monitoring system for body excretion. Proceeding of National Seminar on Technology and Engineering, Muhammadiyah University Malang, Malang, 2019.

[4] W. Isnaeni, Animal physiology. Yogyakarta, PT Kanisius, 2006.

[5] W.J. Bacha, L.M. Bacha, Atlas of Veterinary Histology, Blackwell Publishing, London, 2006.

[6] S. Tanuwidjaya, Textbook of Child Falling, IDAI, Jakarta, 2002.

[7] R.A. Nugroho, Textbook of animal development reproduction, Cahata Atma, Yogyakarta, 2015.

[8] R. Bellairs, M. Osmond, M. The atlas of chick development, Elsevier, USA, 2014.

[9] R.D. Kurnia, A. Nuriliani, Histological structure and histomorphometry of stingray wader fish kidneys (Rasbora lateristriata Bleeker, 1854) at pre-stage mature and mature. Thesis. Gadjah Mada University, Yogyakarta, 2014.

[10] A. Kusumawati, R, Febriany, S. Hananti, M.S. Dewi, N. Istiyawati, Embryonic development and sex determination of DOC (day-old chicken) super Javanese chicken. J. Vet. Sci. 34(1) (2016) 29-41.

[11] J.A. Kiernan, Histological and histochemical methods: Theory and practice. $2^{\text {nd }}$ ed, Pergamon Press, Oxford, 1990.

[12] B.B. Purnomo, Fundamentals of urology, $2^{\text {nd }} \mathrm{Ed}$, Sagung Seto, Jakarta, 2009.

[13] W. Azani, Zainuddin, E. Rahmi, Histological features of the urinary system of Cork fish (Channa striata). JIMVET 1(4) (2017) 709-714.

[14] C. Nutriana, S. Jatman, Study of the kidney 
anatomy of bird's nest white (Collocalia fucipaga) and sriti (Collocalia linchi). J. Vet. Sci. 28(2) (2010) 55-62.

[15] L.C.U. Junqueira, J. Carneiro, Basic Histology, Lange Medical Publications, California, 1980.

[16] Surjono, Embryonic development process. University Publishing Center, Jakarta, 2001.

[17] H.H. Nguyen, T.M. Tumpey, H.J. Park, Y.H. Byun, L.D. Tran, V.D. Nguyen, P.E. Kilgore, C. Czerkinsky, J.M. Katz, B.L. Seong, J.M. Song, Y.B. Kim, H.T. Do, T. Nguyen, C.V. Nguyen, Prophylactic and therapeutic efficacy of avian antibodies against influenza virus $\mathrm{H} 5 \mathrm{~N} 1$ and H1N1 in mice. PloS ONE 5(2010) e10152.

[18] F. Takashima, T. Hibiya, An atlas of fish histology, $2^{\text {nd }}$ Ed, Kodansha LTD, Tokyo, 1995.

[19] G.T. Wardani, Histopathological studies of the effect of the Streptococcus agalactiae vaccine which irradiated the liver and kidneys of mice (Mus musculus), Thesis, Faculty of Veterinary Medicine, Bogor Agricultural University, Bogor, 2012.

[20] R. Mayori, N. Marusin, D.H. Tjong, The effect of giving rhodamine $\mathrm{B}$ on the histological structure of the kidneys of white mice (Mus musculus L.), Jurnal Biologi Universitas Andalas 2(1) (2013) 43-49. 